\title{
A study of the release of active peptide from semisolid hydrogels measured with Franz diffusion apparatus
}

\author{
Beata Łubkowska ${ }^{1}$ Justyna Strankowska², Zbigniew Maćkiewicz ${ }^{3}$, Beata Grobelna ${ }^{4}$
}

\author{
${ }^{1}$ Department of Physiotherapy and Health Sciences, Gdansk Management College, \\ Gdansk, Poland \\ ${ }^{2}$ Institute of Experimental Physics, Faculty of Mathematics, Physics and Informatics, \\ University of Gdansk, Gdansk, Poland \\ ${ }^{3}$ Department of Molecular Biotechnology, Faculty of Chemistry, University of Gdansk, \\ Gdansk, Poland \\ ${ }^{4}$ Department of Chemistry and Analytics Cosmetics, Faculty of Chemistry, University \\ of Gdansk, Gdansk, Poland
}

Submitted: 9 July 2017

Accepted: 27 January 2018

Arch Med Sci Aging 2018; 1: e12-e18

DOI: https://doi.org/10.5114/amsa.2018.78777

Copyright (c) 2018 Termedia \& Banach

\section{Abstract}

Introduction: Recently there has been a growth of interest in novel skin care formulations containing active ingredients, such as low molecular weight peptides. In this paper we present new skincare formulations of hydrogels containing a tetrapeptide ( $N$-Pro-Val-Ala-Gly). Low molecular peptides evolved from research into wound healing and studies on growth stimulation of human skin fibroblasts. The main aim of our study was to perform tests of release of the peptide through synthetic membrane and assessment of the rate of release of peptide from hydrogels from different recipes.

Material and methods: The peptide was identified (ion mass, productivity, homogeneity) and the formulations were characterized in terms of physicochemical parameters. Permeation studies were conducted using Franz diffusion cells. The collected samples were subjected to determination by the MALDI-TOF-MS method and the analytical HPLC technique. The ex vivo tests allow for testing of active substances outside a living organism while representing the effects of these compounds on the organism.

Results: The results showed that the properties of the formulations strongly determined the release rate of the tetrapeptide. Furthermore, lemon essential oil modified the penetration of the peptide through membranes which we used.

Conclusions: The presence of the lemon essential oil in the formulations reduced the time of penetration of the lipophilic peptide.

Key words: low molecular peptides, diffusion test, semisolid hydrogels.

\section{Introduction}

Nowadays, low molecular weight peptides are common active components of semisolid formulations. These compounds have recently revolutionized the skincare and pharmaceutical industries and have become one of the major bioactive ingredients in anti-aging cosmetic compositions [1]. Peptides are formed from amino acids which mimic fragments of endogenous peptides that exhibit biological activity [2]. Low molecular peptides evolved from research into wound healing and studies on growth stimulation of human skin fibroblasts. Advanced research on the cellular and

\author{
Corresponding author: \\ Beata tubkowska \\ Department of \\ Physiotherapy and \\ Health Sciences \\ Gdansk Management College \\ 7 Pelplinska St \\ 80-335 Gdansk, Poland \\ E-mail: beata.lubkowska@ \\ wsz.pl
}


biochemical processes of aging and wounded skin may generate new strategies to manipulate these processes for therapeutic clinical effect $[3,4]$.

Peptides can cause different effects on the skin, but one important hurdle to obtaining effects within the skin is difficulty to penetrate the epidermis [5, 6]. Generally, permeation ability depends on different factors: physicochemical properties of the substance (acid dissociation constant (pKa), molecular size, stability, binding affinity, solubility and partition coefficient); the time-scale of permeation; integrity, thickness and components of the skin, cutaneous metabolism; site, area and duration of application; properties of the transdermal device and the creation of a local depot at the site of application [7-9].

Nowadays, the penetration behaviour of all ingredients can be evaluated by in vitro, ex vivo, and in vivo methods. An ex vivo diffusion cell system is often used all over the world to evaluate the percutaneous permeation of active or potentially toxic ingredients of cosmetic products. It is known that penetration of active ingredients of cosmetics into skin is usually very difficult. Active ingredients for which this rule is true often have a high molecular mass (> $500 \mathrm{Da}$ ) [10, 11]. In this study we used Franz cells as equipment for ex vivo skin permeation of peptide studies.

Franz diffusion cells are normally used with excised human or animal skin. However, when biological skin is not readily available, synthetic membranes are employed. Either way, the membranes have two functions: simulation of the skin and quality control [12-14]. Usually, the porous synthetic membranes used (e.g., cellulose acetate) in Franz diffusion cells are 'borrowed' from separation and filtration applications. In the literature, investigators have employed synthetic membranes of a diverse range of materials. The best results are obtained for membranes characterised by high porosity and minimum thickness and are neutral for formulation [15-17].

In the present study, in order to obtain reliable assessment of diffusion of the peptide through the membrane, the experiment was conducted under standard laboratory conditions by the same operator. The release of the peptide was tested in two different semisolid hydrogels on the Franz cell apparatus. We used synthetic membranes of cellulose acetate which were extracted in a mixture of liposomes.

\section{Material and methods}

\section{Material}

The tetrapeptide with the sequence N-Pro-ValAla-Gly was synthesized according to the procedure of solid phase peptide synthesis (SPPS). The crude peptide was purified and characterized by the analytical techniques reverse phase highperformance liquid chromatography (RP-HPLC) (Beckman Gold System) and mass spectrometry by matrix assisted laser desorption ionization (MALDI-TOF-MS).

Furthermore, in order to determine the physicochemical properties, we used plates preparative to thin layer chromatography (TLC) in the following chromatographic system: methanol : acetic acid $(20: 1, v / v)$. Physicochemical properties of peptide are shown in Table I.

\section{Formulation of hydrogels}

The recipe of semisolid hydrogel were prepared as specified in Table II. Two of these formulations contained synthesised peptide. Summary, we obtained four cosmetic formulations. Every time $50 \mathrm{~g}$ of hydrogel masks were obtained using the following technique: carbomer was dispersed in water by gently scattering it on the surface of water, allowing it to be moisturized (for at least 10 minutes), then briefly mixed. Phenonip ${ }^{\oplus}$ was added and mixed thoroughly using a mechanical stirrer at low speed for 20 min. The next step was to dissolve the tetrapeptide in water and place it in the hydrogel formulation. Subsequently everything was thoroughly stirred for $10 \mathrm{~min}$. $\mathrm{pH}$ was checked and the final stage triethanolamine was added until the $\mathrm{pH}$ reached about 6 . In case of hydrogels II the lemon essential oil was added together with triethanolamine.

The lemon essential oil was chosen because of the favorable properties of the sorption promoter. But lots of scientific studies confirm the beneficial properties of lemon oil. Among them are exchanged it has properties of refreshing, antiseptic, toning, antipruritic, sealing and bleaching effects. It fights both viruses and bacteria. In addition, it relieves nervous tension and has a firming, soothing and calming effect. It also closes the skin pores and helps the immune system.

The influence of D-limonene, which is the main ingredients lemon oil did not be checked.

Table I. Physicochemical properties of peptide

\begin{tabular}{|c|c|c|c|c|c|}
\hline \multirow[t]{2}{*}{ Sequences of peptide } & \multicolumn{2}{|c|}{ Ion mass $[\mathrm{m} / \mathrm{z}]$} & \multirow{2}{*}{$\begin{array}{l}\text { Peptide mass } \\
\text { [mg] }\end{array}$} & \multirow{2}{*}{$\begin{array}{c}\text { Productivity } \\
\text { [\%] }\end{array}$} & \multirow[t]{2}{*}{$\operatorname{TLC}\left[R_{f}\right]$} \\
\hline & Calculated & Designated & & & \\
\hline N-Pro-Val-Ala-Gly & 342 & $\begin{array}{c}343.4[M+1] \\
365.3[M+23]\end{array}$ & 448 & 89 & 0.63 \\
\hline
\end{tabular}


Table II. Chemical compositions of the formulations

\begin{tabular}{|c|c|c|c|c|}
\hline No. & Sample name & Composition [INCI] & Company & $\begin{array}{c}\text { Quantity } \\
\text { [\%wt., } \pm 0.01 \text { ) }\end{array}$ \\
\hline \multirow[t]{4}{*}{1} & Semisolid hydrogel I & Distilled water & & 98.7 \\
\hline & & Carbomer & Lubrizol, S\&D Poland & 0.60 \\
\hline & & Triethanolamine & POCH SA & 0.40 \\
\hline & & Phenonip & Clariant UK Ltd. & 0.30 \\
\hline \multirow[t]{5}{*}{2} & Semisolid hydrogel II & Distilled water & & 98.65 \\
\hline & & Carbomer & Lubrizol, S\&D Poland & 0.60 \\
\hline & & Triethanolamine & POCH SA & 0.40 \\
\hline & & Phenonip & Clariant UK Ltd. & 0.30 \\
\hline & & Citrus Medica Limonum & Epoch - Nu Skin & 0.05 \\
\hline \multirow[t]{5}{*}{3} & Semisolid hydrogel I + PVAG & Distilled water & & 98.65 \\
\hline & & Carbomer & Lubrizol, S\&D Poland & 0.60 \\
\hline & & Triethanolamine & POCH SA & 0.40 \\
\hline & & Phenonip & Clariant UK Ltd. & 0.30 \\
\hline & & PVAG & & 0.05 \\
\hline \multirow[t]{6}{*}{4} & Semisolid hydrogel II + PVAG & Distilled water & & 98.60 \\
\hline & & Carbomer & Lubrizol, S\&D Poland & 0.60 \\
\hline & & Triethanolamine & POCH SA & 0.40 \\
\hline & & Phenonip & Clariant UK Ltd. & 0.30 \\
\hline & & Citrus Medica Limonum & Epoch - Nu Skin & 0.05 \\
\hline & & PVAG & & 0.05 \\
\hline
\end{tabular}

D-limonene has is also found in cumin and orange essential oils. It has antioxidant, anti-cancer and antibacterial properties. What's more, it inhibits the activity of the elastase enzyme, thus preventing the degradation of elystin and proteins, which together with collagen are responsible for the firmness and elasticity of the skin. Additionally, D-limonene increases the bioavailability of coenzyme Q10.

Finished products were tightly sealed and stored in the fridge at $5^{\circ} \mathrm{C}$.

\section{Rheology of gels}

Rheological measurements of gel viscosity were made at $25 \pm 0.2^{\circ} \mathrm{C}$ and $36.6 \pm 0.2^{\circ} \mathrm{C}$ using a Brookfield RS Portable rotational rheometer in controlled shear rate (CSR), equipped with a plate/ plate measuring system (1 $\mathrm{mm}$ gap). All flow curves were registered with a change in shear rate from 0 to $120 \mathrm{~s}^{-1}$ with preliminary rotation with $10 \mathrm{~s}^{-1}$ angular velocity for $0.5 \mathrm{ml}$ filling volume of sample. RHEO3000 and OriginPro 2016 software was used for data collection and data analysis, respectively. The viscosity curves $\eta(\gamma)$ were fitted using power law (Ostwald de Waele) equations, typical of many pseudoplastic gels: $\eta=k \times(\gamma)^{n-1}$, where $k$ is a consistency index, $n=$ flow behaviour index ( $n<1$ for pseudoplastic materials), $\eta=$ viscosity, $\gamma=$ shear rate $[18,19]$.

\section{Ex vivo release methods}

The Franz diffusion chamber used in this study was made from borosilicate glass with a $2 \mathrm{~cm}$ diameter hole at the centre, the same size as the opening in the vertical receptor cell, which is placed on top of the membrane and then filled with the semisolid.

The porous synthetic membrane made from cellulose acetate $(0.45 \mu \mathrm{m}$ pore size, $115 \mu \mathrm{m}$ thickness) (Whatman) was extracted with a liposome formulation consisting of $10 \mathrm{ml}$ : (INCl): Aqua, Lecithin, D-panthenol, Sorbitol, Trilaureth-4 phosphate, Sodium Carbomer, Ceramide 6, Dipalmitoyl hydroxyproline, Phenoxyethanol, Ethylhexylglycerin. This activity was performed in order to wet pores in the synthetic membrane to reconstruct the natural skin conditions. Liposomes should also facilitate diffusion of the peptide into the acceptor chamber. Liposomes easily overcome the barrier, which for the substance contained in the cosmetics is the skin (in this case, the synthetic membrane). Even a binder which fills spaces between its cells, does not constitute an obstacle to them. As a result, the substances that they are carried through penetrate the barrier of the stratum corneum at higher concentrations and exhibit much stronger action than the same compounds administered in free form [20].

Other synthetic membranes made of nylon were also used during the tests. These, however, were characterized by much lower permeability and their use was abandoned in the further stage of research.

The membrane with the sample of hydrogel with a selected sequence of peptide N-Pro-ValAla-Gly (1 $\pm 0.01 \mathrm{~g})$ was placed on top of the vertical receptor cell and clamped tightly into place. The receptor cell was filled with the dissolution medium and a small Teflon-coated magnetic stirrer was used for mixing. 
Throughout this study, the flow rate was $5 \mathrm{ml} /$ min at a constant temperature of $36.6 \pm 0.5^{\circ} \mathrm{C}$. This temperature was chosen in order to reproduce the hand's physiological temperature in normal conditions. The samples $(2 \mathrm{ml})$ were collected in small tubes at 60 min intervals up to $24 \mathrm{~h}$.

The experiment was repeated 5 times and in each case the results were obtained.

\section{Analysis method}

All collected fractions of peptide N-Pro-ValAla-Gly were tested by reversed-phase high performance liquid chromatography (RP-HPLC) using a Beckman Gold System chromatograph and a $4.6 \mathrm{~mm} \times 150 \mathrm{~mm}, 5 \mu \mathrm{m}$ particle diameter, $100-\AA$ pore size, Kromasil C8 column. The mobile phases were gradients prepared from $0.1 \%$ TFA in acetonitrile (solution $\mathrm{A}$ ) and $0.1 \%$ aqueous TFA (solution B). The gradient was $10-70 \%$ A in 20 to $40 \mathrm{~min}$. The flow rate was $1 \mathrm{ml} / \mathrm{min}$. The presence of peptide $N$-Pro-Val-Ala-Gly was confirmed by the absorption peak at $227 \mathrm{~nm}$.

A

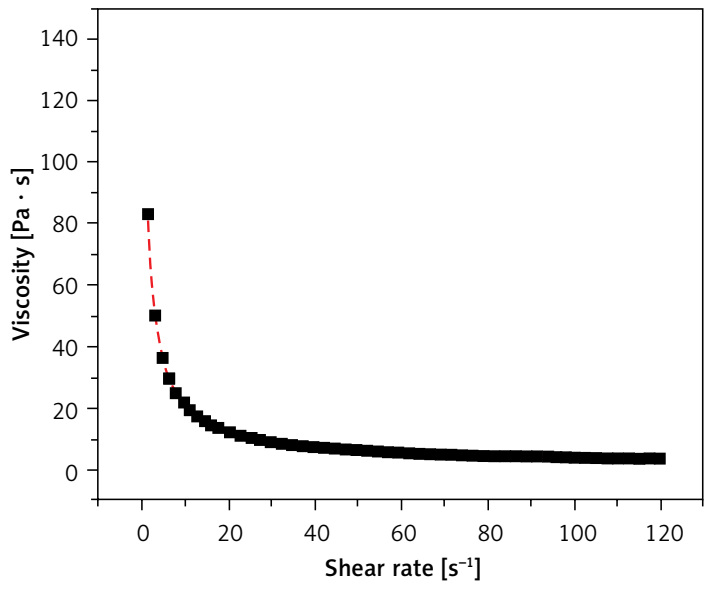

- PVAG $125^{\circ} \mathrm{C}$

C

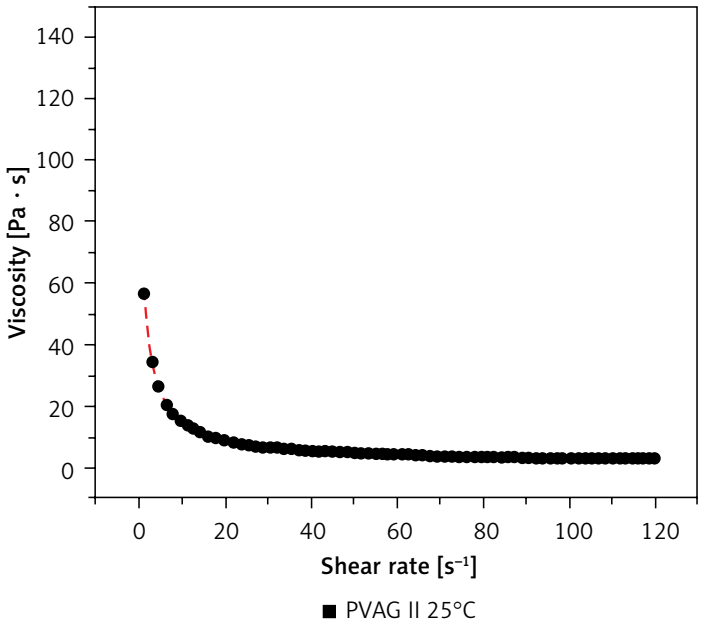

Determination of the molecular ion of peptide $N$-Pro-Val-Ala-Gly was made by using the analytical method mass spectroscopy of laser desorption ionization in the matrix (MALDI-TOF-MS).

\section{Results and discussion}

Active compounds' penetration into the skin is often rather poor. This is especially true for agents of high mass (molecular mass $>500$ ) and high hydrophilicity [21]. Therefore, the form of the cosmetic preparation is also significant. Diverse factors such as size of the dispersed particles, the interfacial tension between the phases, and the rheology of the formulation determine the physical properties of the semisolid dosage form. Moreover, in order to increase the penetration of substances very often the cosmetic recipes use the so-called promoters of penetration. These are compounds that reversibly change the structure of the intracellular matrix of the epidermis by facilitating and sometimes also accelerating the penetration of the substance through the stratum corneum.

\section{B}

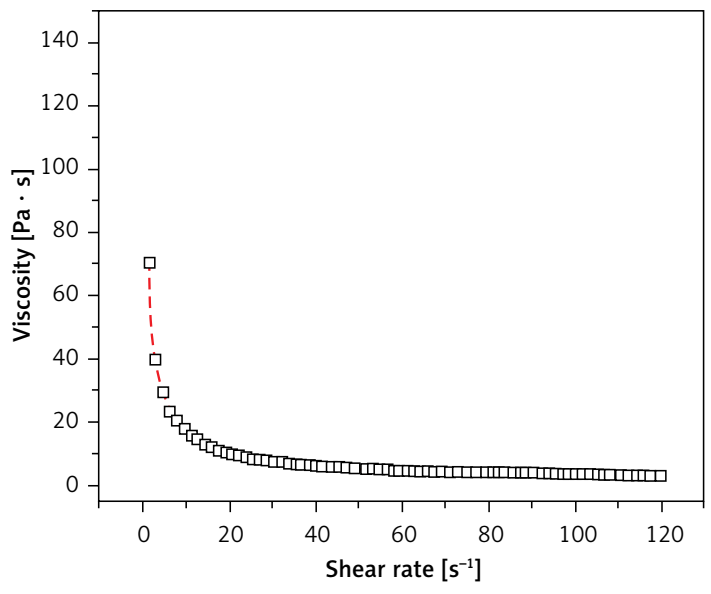

$\square$ PVAG $136.6^{\circ} \mathrm{C}$

D

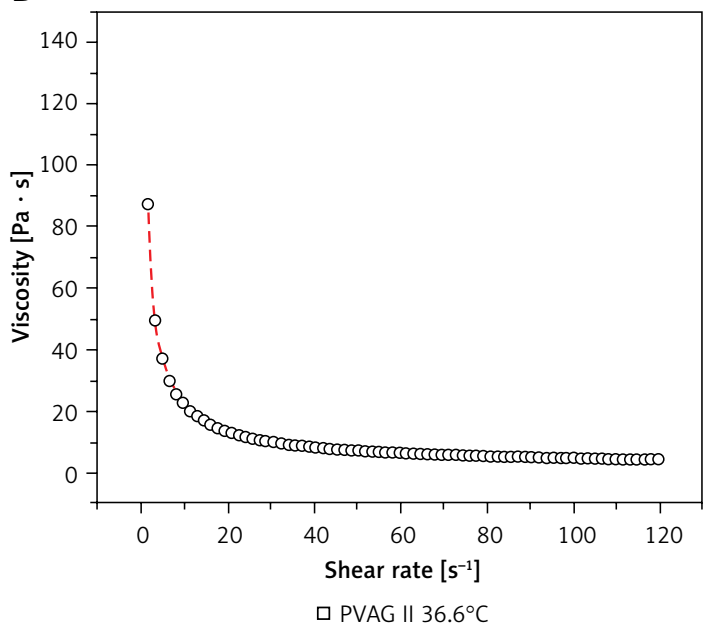

Figure 1. Viscosity curves for semisolid gels at $25^{\circ} \mathrm{C}(\mathrm{A}, \mathrm{C})$ and $36.6^{\circ} \mathrm{C}$ (B, D). Experimental data are fitted Ostwald de Waele equation 
Table III. Values of the rheological parameters $k$ and $n$ for semisolid hydrogels

\begin{tabular}{|lcccc|}
\hline Sample & $k\left[\mathrm{~Pa} \cdot \mathrm{s}^{\mathrm{n}}\right]$ & $\boldsymbol{N}$ & $k\left[\mathrm{~Pa} \cdot \mathrm{s}^{\mathrm{n}}\right]$ & $\boldsymbol{N}$ \\
\cline { 2 - 5 } & \multicolumn{3}{c}{$25^{\circ} \mathrm{C}$} & \multicolumn{3}{c|}{$36.6^{\circ} \mathrm{C}$} \\
\hline PVAG I & $119.34 \pm 0.33$ & $0.2549 \pm 0.0014$ & $99.44 \pm 0.50$ & $0.2450 \pm 0.0026$ \\
\hline PVAG II & $79.89 \pm 0.27$ & $0.2801 \pm 0.0017$ & $124.32 \pm 0.44$ & $0.2390 \pm 0.0019$ \\
\hline
\end{tabular}

For all samples $n>1$, which means that the test gels are pseudoplastic fluids (thinned shear).

Rheological tests are not only a measurement of the hydrogel stability against shear forces, but they also provide important information about the behaviour of the system during skin application [22]. Primarily the hydrogels obtained were examined for viscosity. This is a very important physicochemical parameter, which depends on ease of spreading on the skin, stability and release of active substances from cosmetics.

Viscosity curves of semisolid hydrogels at $25^{\circ} \mathrm{C}$ and $36.6^{\circ} \mathrm{C}$ are presented in Figure 1. Experimental data $\eta(\gamma)$ were fitted using the Ostwald de Waele equation and obtained values of the rheological parameters $k$ and $n$ were collected in Table III. The viscosity of hydrogels decreases, whilst the shear rate increases. This shows that gel samples present non-Newtonian behaviour. The flow index $n$ reaches values $n<1$, which means that all measured semisolid hydrogels behave as pseudoplastic, shear-thinning fluids. Consistency indexes have different values for measured samples. The smallest value of the $k$ parameter was fitted for sample of PVAG II (79.89 Pa $\left.\cdot \mathrm{s}^{\mathrm{n}}\right)$. In this case, the addition of lemon essential oil acted like a plasticizer and increased the distance between the chains and thus reduced the viscosity of the gel.

Obtained $k$ parameter values are higher $(\sim 30$ $\left.\mathrm{Pa} \cdot \mathrm{s}^{\mathrm{n}}\right)$ at $36.6^{\circ} \mathrm{C}$ for semisolid gels $\|+$ PVAG than consistency obtained at $25^{\circ} \mathrm{C}$. We believe that at higher temperatures gelling and additional crosslinking occur. For the PVAG I sample the $k$ parameter decreases $\left(\sim 20 \mathrm{~Pa} \cdot \mathrm{s}^{\mathrm{n}}\right)$ with increasing temperature, which is related to lack of lemon essential oil. The temperature does not influence

A

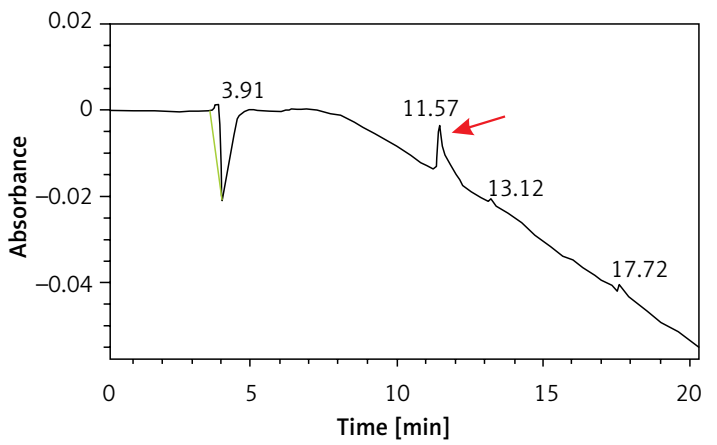

Figure 2. Chromatograph N-Pro-Val-Ala-Gly released from (A) hydrogel I after $24 \mathrm{~h}$, retention time was 11.57 min, (B) hydrogel II after $21 \mathrm{~h}$, retention time was $11.41 \mathrm{~min}$ flow indexes, which confirms the rheological stability of the gels during application.

The present study investigated the skin penetration of peptide using prepared "artificial skin" in an ex vivo diffusion cell system. We studied the influence of contained compounds in the lemon essential oil on the permeation rate of peptide. The main ingredient in lemon oil is d-limonene monoterpenic hydrocarbon, which accounts for up to $90 \%$ of the essential oil. This component exhibits the properties of the penetration promoter, increasing the permeability of the stratum corneum by inducing reversible changes in the skin structure. Ingredients occurring in smaller quantities $(2-7 \%)$ include $\beta$-pyrene, $\alpha$-pinene, $\gamma$-terpinene, neral and geranial. The latter two are responsible for the intense lemon scent of the essential oil [23].

The samples, which were taken from the acceptor diffusion chamber, were analysed by the techniques of MALDI-TOF-MS and HPLC.

The HPLC chromatograms (Figure 2) contain characteristic peaks corresponding to peptide $N$-Pro-Val-Ala-Gly. The retention time was the same as we received during research of crude peptide and during its purification process (11.50 min).

At the second study, we obtained MS spectra of peptide (Figure 3) after penetration through the membrane. Observed peaks corresponded to molecular weight of peptide Pro-Val-Ala-Gly. These peaks are low intensity due to the small amount of the oligopeptide that had penetrated into the solution. Furthermore, due to the low concentration of the peptide in the formulations, the peaks of Pro-Val-Ala-Gly are located on the border of noise matrix of CCA. In addition to the

B

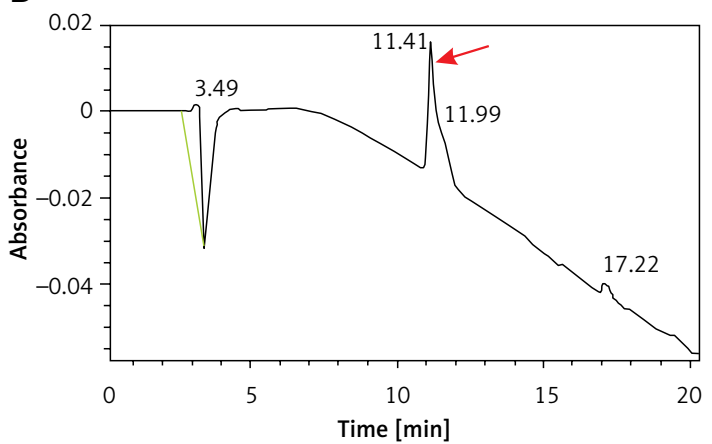

(A) hydrogel I after $24 \mathrm{~h}$, retention time was $11.57 \mathrm{~min}$, 
A

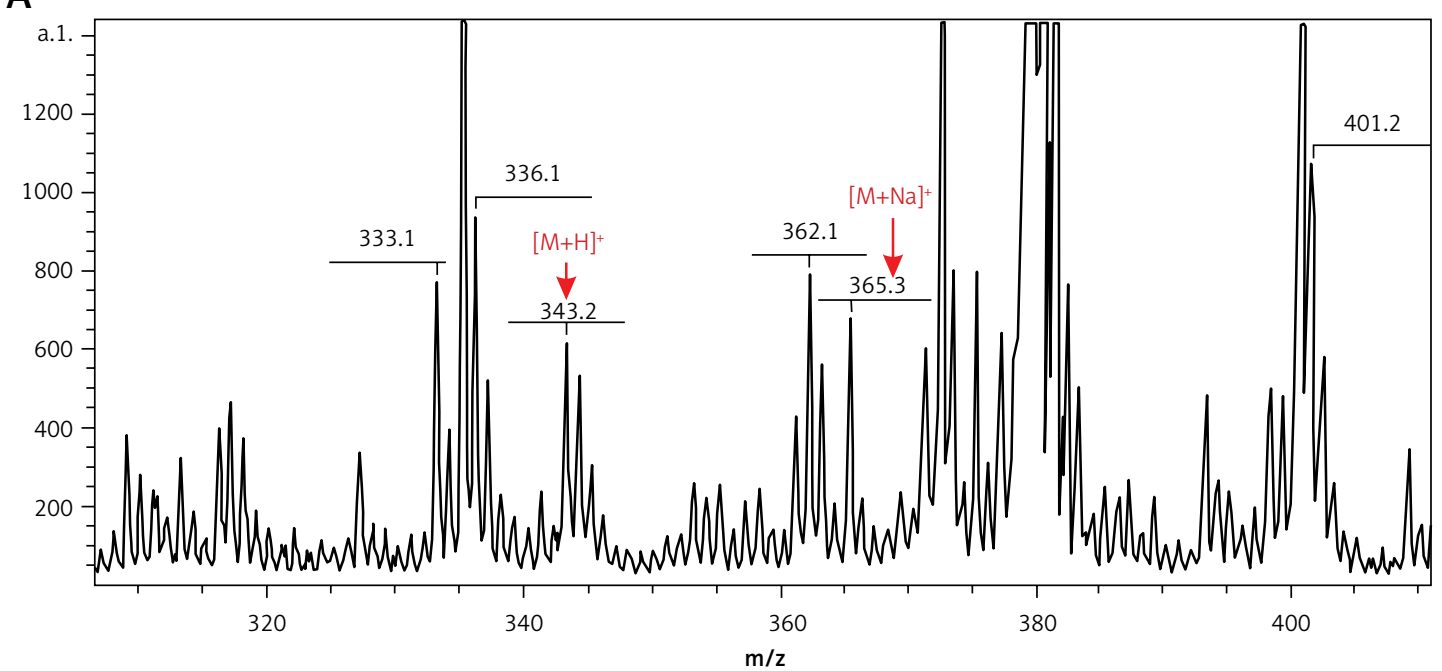

B

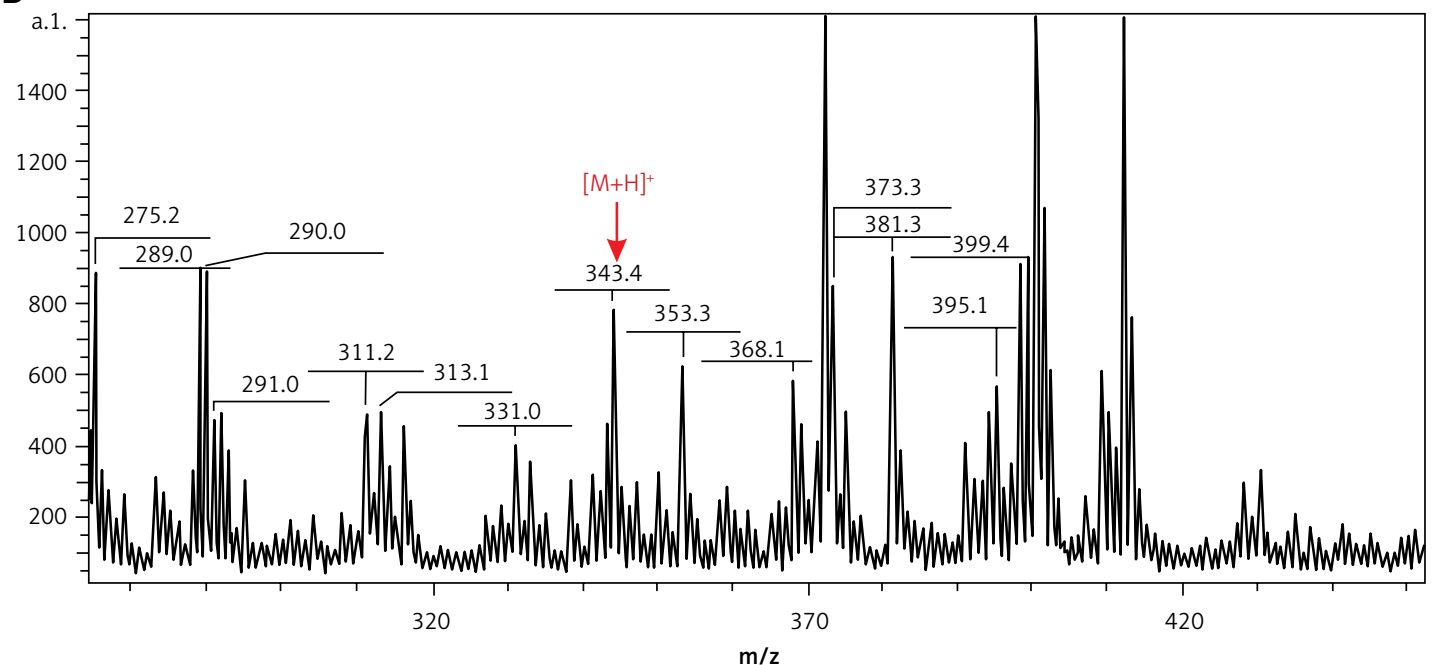

Figure 3. Spectra mass $\mathrm{N}$-Pro-Val-Ala-Gly released from (A) hydrogel I after $24 \mathrm{~h}$, peak $\mathrm{m} / \mathrm{z}=343.2$ belongs to $[\mathrm{M}+\mathrm{H}]^{+}$, peak $\mathrm{m} / \mathrm{z}=365.3$ belongs to $[\mathrm{M}+\mathrm{Na}]^{+}$and $(\mathrm{B})$ hydrogel II after $21 \mathrm{~h}$, peak $\mathrm{m} / \mathrm{z}=343.4$ belongs to $[\mathrm{M}+\mathrm{H}]^{+}$

peak of the tetrapeptide, there appear peaks demonstrating the penetration of other compounds present in the test sample. The investigated oligopeptide was released faster from the semisolid gel II.

Tetrapeptide N-Pro-Val-Ala-Gly is a lipophilic compound, and can interact with lipids. In the case of the release of this peptide from semisolid gel I, the smallest release can be observed. It is connected with the nature of hydrogel I, which contains only hydrophilic ingredients. However, in the case of the release of the peptide from hydrogel II, faster release of peptide can be observed.

The compounds which are contained in essential oils interpose themselves between the hydrophobic lipid chains, creating new spaces suitable for the penetration of active substances. Consequently, a shift of lipid particles is possible, and easier diffusion of applied compounds is observed. The findings of this study provide new in- formation on N-Pro-Val-Ala-Gly penetration. First, there is experimental evidence for ex vivo peptide skin permeation. Moreover, there is an appreciable increase in permeation for this peptide in the presence of essential oil.

In conclusion, the penetration of substances is a complex process, which is influenced by many factors. Understanding the process of penetration of the oligopeptides across the stratum corneum, ex vivo using diffusion cells, is extremely important in the design of new cosmetics. For the majority of cosmetics the site of action is the skin surface and stratum corneum. Preparation of the liposome membrane layer and rollers of cellulose acetate enabled creation of an artificial construct of skin which allowed the examination of penetration of the selected oligopeptides. The method used and the test conditions permeability compounds using the Franz chamber, characterized by reproducibility and repeatability of results. Applying the release 
of oligopeptides with hydrogel techniques such as HPLC and MALDI-TOF-MS allowed confirmation of the presence of the oligopeptide in the test sample fluid acceptor.

The "model" membrane flesh was sufficiently thin and highly porous for there to occur oligopeptide release of hydrogels. The constructed used skin was chemically inert relative to the examined cosmetic and acceptor fluid. The use of films formed from natural polymers such as cellulose derivatives enables the continual release of oligopeptide hydrogel cosmetics.

The permeability of the peptides through the epidermal barrier depends largely on the peptide sequence but, also in a large extent from the other ingredients of the cosmetic product. Due to the lipophilic and acidic nature of the epidermis, a modification of tetrapeptide was made with palmitic acid (Palm) or an acyl group (Ac). The research confirmed that it was not the modifications, but the sorption promoter used for this peptide, that caused a greater penetration through the skin. In our experiment, the addition of essential oil was reduce the time of penetration of the hydrophobic peptide.

\section{Conflict of interest}

The authors declare no conflict of interest.

\section{References}

1. Lupo MP, Cole AL. Cosmeceutical peptides. Dermatol Ther 2007; 20: 343-9.

2. Buraczewska I, Berne B, Lindberg M, et al. Changes in skin barrier function following long-term treatment with moisturizers, a randomized controlled trial. $\mathrm{Br}$ J Dermatol 2007; 156: 492-8.

3. Łubkowska B, Grobelna B, Maćkiewicz Z. Synthesis of alpha-collagen fragments and research their influence on hydration degree of a model of epidermis. Adv Dermatol Allergol 2013; 30: 6-12.

4. Danquah MK, Agyei D. Pharmaceutical applications of bioactive peptides. OA Biotech 2012; $1: 5$.

5. Lintner K, Peschard O. Biologically active peptides: from a laboratory bench curiosity to a functional skin care product. Int J Cosm Sci 2000; 22: 207-18.

6. Gorouhi F, Maibach HI. Role of topical peptides in preventing or treating aged skin. Int J Cosm Sci 2009; 31: 327-45.

7. Olejnik A, Schroeder G, Nowak I. The tetrapeptide Nacetyl-Pro-Pro-Tyr-Leu in skin care formulations - physicochemical and release studies. Int J Pharm 2015; 492 . 161-8.

8. Yang Y, Wang S, Xu H, et al. Properties of topically applied organogels: rheology and in vitro drug release. Asian J Pharm Sci 2008; 3: 175-83.

9. Bonacucina G, Cespi M, Misici-Falzi M, et al. Rheological, adhesive and release characterization of semisolid Carbopol/tetraglycol system. Int J Pharm 2006; 307: 129-40.

10. Küchler S, Radowski MR, Blaschke T, et al. Nanoparticles for skin penetration enhancement - a comparison of a dendritic core-multishell-nanotransporter and solid lipid nanoparticles. Eur J Pharm Biopharm 2009; 71: 243-50.

11. Magnusson BM, Anissimow YG, Cross SE. Molecular size as the main determinant of solute maximum flux across the skin. J Invest Dermatol 2004; 122: 993-9.

12. Twist JN, Zatz JL. Membrane - solvent - solute interaction in a model permeation system. J Pharm Sci 1988; 77: 538-40.

13. Twist JN, Zatz JL. Influence of solvents on paraben permeation through idealized skin model membranes. J Soc Cosmet Chem 1986; 37: 429-44.

14. Corbo M, Schultz TW, Wong GK, et al. Development and validation of in vitro release testing methods for semisolid formulations. Pharm Tech 1993; 9: 112-28.

15. Addicks WJ, Flynn GL, Weiner N. Validation of a flowthrough diffusion cell for use in transdermal research. Pharm Res 1987; 4: 337-41.

16. Gallagher SJ, Trottet L, Carter TP, Heard CM. Effects of membrane type and liquid/liquid phase boundary on in vitro release of Ketoprofen from gel formulations. J Drug target 2003; 11: 373-9.

17. Igielska-Kalwat J, Nowak I. Release of active ingredients from cosmetic emulsions. Chemik 2015; 69: 498-504.

18. Rao AM. Rheology of fluid, semisolid, and solid foods: principles and applications. In: Flow and Functional Models for Rheological Properties of Fluid Foods. Springer US, 2014; 27-61.

19. Schramm G. A Practical Approach to Rheology and Rheometry. Gebrueder Haake, Karlsruhe, Germany 1994.

20. Available at: http://www.ebusy.nazwa.pl/centrumkosmetologii/liposomy.html

21. Kuchler S, Radowski MR, Blaschke T, et al. Nanoparticles for skin penetration enhancement - a comparison of a dendritic core-multishell-nanotransporter and solid lipid nanoparticles. Eur J Pharm Biopharm 2009; 71: 243-50.

22. Moravkova PFT. The influence of emulsifier on rheological and sensory properties of cosmetic lotions. Adv Mater Sci Eng 2013; 2013: 1-7.

23. Dugo P, Mondello L, Stagno d'Alcontres I, et al. Oxygen heterocyclic compounds of citrus essential oils. Perf Flav 1997; 22: 25-30. 